\title{
A Load Flow based Approach for Optimum Allocation of Distributed Generation Units in the Distribution Network for Voltage Improvement and Loss Minimization
}

\author{
Nibedita Ghosh \\ P.G Scholar \\ EE Deptt., NIT Agartala
}

\author{
Sharmistha Sharma \\ Assistant Professor \\ EE Deptt., NIT Agartala
}

\author{
Subhadeep Bhattacharjee \\ Assistant Professor \\ EE Deptt., NIT Agartala
}

EE Deptt., National Institute of Technology Agartala, Barjala, Jirania, Tripura (west), Pin: - 799055

\begin{abstract}
DG is nothing but a small scale generation unit connected directly to the distribution network or near customer load center. This system may or may not be connected to the electric grid. DG has a limited size of 10MW or less especially when DG is used in a distribution network. DG is installed at the place where it becomes impracticable to build a central generation plant. DG is installed to improve the voltage profile as well as minimize losses. DG allocation is a crucial factor. Optimum DG allocation provides a variety of benefits. But inappropriate DG allocation can cause low or over voltage in the network. In this paper a load flow based method using ETAP software is used to determine the optimum location \& optimum size of DG in a 33 bus distribution system for voltage profile improvement $\&$ loss reduction.
\end{abstract}

\section{Keywords}

Distributed Generation, ETAP, load flow algorithm, loss reduction, optimum location, voltage profile improvement.

\section{INTRODUCTION}

Distributed generation is related to the use of small generation units installed in strategic points of the electric power system and mainly, close to load centers. DG can be used in an isolated way, supplying the consumer's local demand or in an integrated way, supplying energy to the remaining of the electric system. In distribution systems, DG can provide benefits for the consumers as well as for the utilities, especially in sites where the central generation is impracticable or where there are deficiencies in the transmission system. A distributed power unit can be connected directly to a utility's transmission or distribution system or to consumer's terminal. Distributed generation is not centrally planned, today not centrally dispatched; it is usually connected to the distribution network $\&$ it's size may be smaller than 50 or $100 \mathrm{MW}[1]$.

Rural electricity supply has been suffering for many years. It becomes possible for Government to provide electricity to $31 \%$ of rural households only \& the supply suffers from frequent power cuts \& high fluctuations in voltage \& frequency. It is necessary to double the present capacity i.e. install an additional generation capacity of $100,000 \mathrm{MW}$ by 2012 .The farmers also complain to Government for electricity problems as the electricity supplied to the rural areas is intermittent \& of poor power quality leading to high implicit costs because of damage to their equipment and downtime. The present policies of building large centralized generation and extended distribution networks are not the proper and economic way to solve the problems of rural electricity supply, at near future.
Decentralized power generation close to rural load centers using renewable sources appears to have the potential to address at least some of the problems of rural electrification[2].There are a few number of DG technologies are still in research \& development stage but a large number of DG technologies are available in the market today. Some currently available technologies are reciprocating engines, micro turbines, combustion gas turbines, fuel cells, photovoltaic \& wind turbines. Each of these technologies has it's own benefits \& characteristics [3]. Employing DG in a distribution system has several advantages and few disadvantages as discussed below:

- DG can reduce line losses.

- DG is installed for voltage profile improvement.

- DG is used to reduce emissions of pollutants.

- Overall energy efficiency is increased using DG.

- Enhanced system reliability and security.

- Power quality is improved after installing DG in the system.

- Enhanced productivity.

- Relieved transmission and distribution congestion after installation of DG.

- A reduced health care cost due to improved environment is possible through DG installation.

- DG can reduce fuel costs due to increased overall efficiency.

- $\quad$ DG can reduce reserve requirements.

- It provides lower operating costs due to peak shaving.

- DG can increase the system security for critical loads

The disadvantages are discussed below

- The system can face reverse power flow as a result of connecting DG at non optimum place.

- Asynchronous DG sources which use inverters for interconnection can cause harmonic injection into the system.

- Stability issues may arise after DG installation.

- Increased fault currents depending on the location of DG units [3].

\section{REVIEW OF LITERATURE}

The type \& operation characteristics of the DG affect the influence on the control \& stability. If the DG is properly coordinated with the available voltage $\&$ reactive power equipment, a proper voltage regulation can still be maintained with the presence of DG. Recent changes in the electric utility infrastructure have created opportunities for many 
technological innovations, including the employment of DG to achieve a variety of benefits. Proper location of DGs in power system is important for obtaining their maximum potential benefits. The problem of optimum location and optimum sizing of DGs has been addressed in various references cited. Ref [4] describes a successive elimination algorithm to place \& size the DGs. Ref [5] a new heuristic approach based on cost benefit analysis for determining the optimum DG size \& location. Ref [6] describes a mixed integer programming (MIP) formulation with branch \& bound optimization for an industrial power plant. Ref [7] describes a Genetic Algorithm (GA) based optimization for deploying a DG resource in a distribution system. Ref [8] describes a frame work for embedded generation planning in line with special emphasis on risk \& uncertainties. Ref [9] proposes DG capacity based on risk factor \& addresses the reliability issues which arise as a consequence of transmission bottle-necks. The problem of determining the capacity \& location of DG has been formulated to minimize the cost of power, energy loss \& the total required reactive power is described in ref [10].Authors in [11] have presented an approach to determine the proper location for fuelled-gas turbine plants in an electric system. An algorithm has been proposed by Gandomkar et al [12] to determine optimum location \& size of DGs, which minimizes the power losses for a fixed number of DGs \& a specific total capacity of DGs. Another method for proper location \& sizing of DG units in a micro grid has been developed in [13], which based on stipulated reliability criteria. An approach for the design of grid connected DG systems is used to satisfy on site reliability \& environmental requirements are proposed in [14].A software has been presented in[15] which provides support for decision making concerned the choice of the ratings \& proper location of DG based on several objectives \& constraints. Ref [16] also targets the problem of DG capacity \& allocation in order to achieve a good compromise between the costs of network upgrading, power losses, energy not supplied $\&$ power quality.

The aim of this work is to find the proper place for DGs in order to improve the voltage profile of the entire system \& minimize the losses in the distribution system. The method consists of 2 sections \& is based on load flow. The proposed method is tested on a 33 bus test system. It is a 33 bus test system with the total load of 3.772MW \& 2.310Mvar.A suitable software (ETAP7.5) is used to analyze the load flow based method for a 33 bus test system. DG allocation studies are relatively new, unlike capacitor allocation. The Genetic Algorithm (GA) based method has already studied to determine the size \& location. GA's are suitable for multi objective problems like DG allocation, \& can give near optimal results, but they are computationally demanding \& slow in convergence. Graffin uses a loss sensitivity factor method \& Naresh Acharya proposes an analytical method to determine the optimal size \& location of DG in distribution networks.

\section{THE PRESENT SCENARIO OF POWER PRODUCTION IN INDIA}

The average electricity consumption in INDIA is about 630 $\mathrm{KWh}$ per person per year; it is still among the lowest per person consumption in the world. But the power consumption is expected to grow to $1000 \mathrm{KWh}$ per person year in the near future. According to Central Electricity Authority (CEA), the peak electricity demand in 2008 was $120 \mathrm{GW}$ of power, while only $98 \mathrm{GW}$ of power could be supplied. According to an analysis by the Indian PV project developer Astronfield, this deficit is likely to grow to $25 \mathrm{GW}$ by 2012 . The government is also making serious efforts to accumulate the growth of renewable's contribution to power.

The current power production status in India:

- India's current installed capacity (end of 2010) is 1,70,229 MW, from all sources.

- Power generation capacity mainly depends on thermal \& hydro, with about $11 \%$ from renewable energy.

- In 2010, peak power storage was $12 \%$.

- Electricity demand is expected to rise by $7.4 \%$ a year during the next quarter of a country.

Status of Indian renewable power generation:

Total installed capacity of renewable power sources [As of Feb 2011, India has over $18.36 \mathrm{GW}$ of installed renewable energy capacity. Wind represents about $13 \mathrm{GW}$, small hydro represents $2.8 \mathrm{GW}$ and the majority of the remainder is from biomass installations. Total electricity installed capacity is 171.9 GW (Feb 2011)

Table 1. \% Share in installed capacity

\begin{tabular}{|c|c|}
\hline Energy source & $\begin{array}{c}\text { \% Share in installed } \\
\text { capacity }\end{array}$ \\
\hline Thermal & $64.75 \%$ \\
\hline Nuclear & $2.78 \%$ \\
\hline Hydro (large hydro) & $21.73 \%$ \\
\hline $\begin{array}{c}\text { Other renewable energy } \\
\text { sources }\end{array}$ & $10.73 \%$ \\
\hline
\end{tabular}

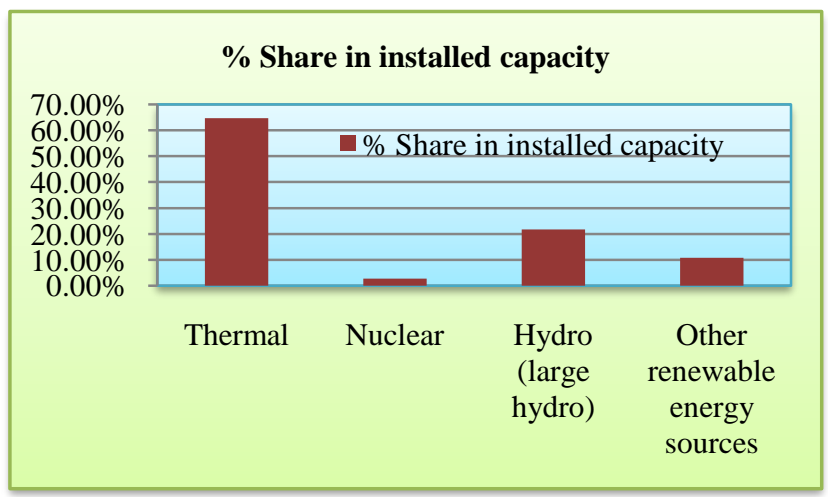

Figure 1: \% Share in installed capacity

\section{ALLOCATON OF DG FOR VOLTAGE PRIFILE IMPROVEMENT \& LOSS MINIMIZATION}

Optimal allocation (sizing \& sitting) of DG at the existing distribution network is very important factor in the planning and operation of active distribution network as optimum DG location can improve voltage profile and to minimize power loss. Voltage profile of a system can be improved by introducing DG unit because DG can provide a portion of real and reactive power to the load locally [17]. Power loss in a system depends on numerous factors such as system configuration, such as level of losses through transmission and distribution lines, transformers, capacitors, insulators etc. There

are two categories of power losses, one is real power loss and another is reactive power loss. Real power loss is caused due to the resistance of lines and reactive power loss is caused due to reactive elements. Real power loss reduces the efficiency of transmitting energy to customers. Reactive power loss is also 
important. Reactive power flow in the system needs to be maintained at a certain level for sufficient voltage level. It is possible to transfer real power to customers through transmission and distribution lines. The level of power losses are also affected from different types of load connected to distribution feeders. The problem which may be found in the distribution network is the problem of voltage drop that must be reduced to keep the voltages at load points with in standard limits. The voltage drop problem is caused due to long distance of feeder or feeding large loads. The best solution of this problem is that the voltage at different nodes of the system must be controlled. The voltage control implies reactive power control. Power loss in a system could be reduced by controlling the reactive power and regulating the node voltages. To improve the voltage and to control the reactive power, the distribution systems are equipped with a voltage control device such as DG implementation [18].Abnormal voltage in the distribution network is produced due to allocation of DG at non optimum places in the network. But optimum location of DG in a distribution network can provide several benefits such as voltage profile improvement, loss minimization, power quality improvement, contributing for frequency regulation and acting as spinning reserve in main system [19].

\section{SIMULATION TECHNIQUE}

The paper presents 3 different procedures. Out of 3 procedures, one is used to find the optimum DG location in a 33 bus distribution system to improve the voltage profile only. Another procedure is used to find the optimum DG location in a 33 bus distribution system to improve the voltage profile as well as loss minimization in the system. Last one is used to find the optimum DG size in the distribution system to maintain a minimum loss as well as voltage profile improvement. All the procedures are tested on a 33 bus distribution system. It is a 33 bus test system with the total load of 3.772 MW and 2.310 MVar. Simulation is done using ETAP software to solve the load flow based algorithm of a 33 bus distribution system.

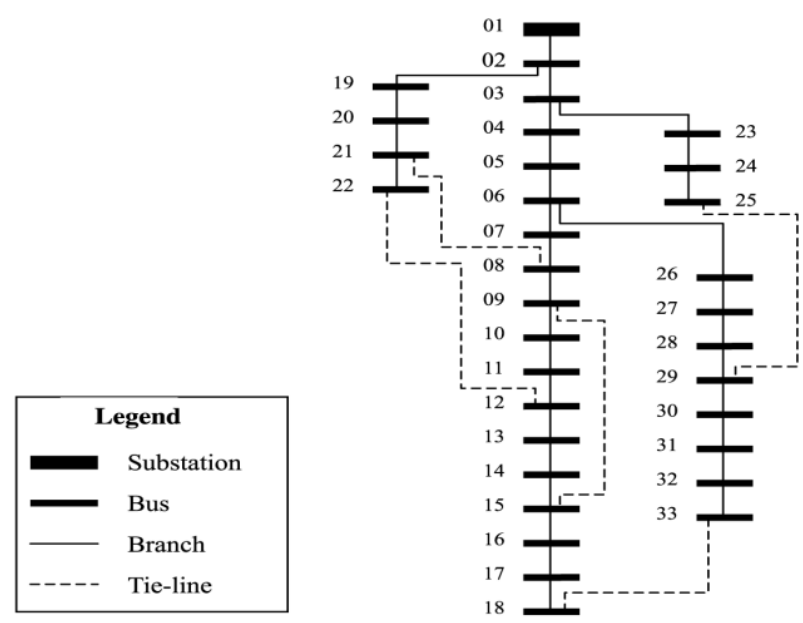

Figure 2: A Single line diagram of 33 bus distribution system

\subsection{First Procedure}

First procedure adopted here is a load flow based method for optimal location of Dispersed Generation units only for voltage profile improvement.

\subsubsection{Proposed Methodology}

To find the proper DG allocation in a 33 bus distribution system for voltage profile improvement is the main aim of this procedure. The method is a combination of 2 sections and is based on load flow. The sensitive buses to voltage (the buses that have a low voltage magnitude) are considered and ranked in the first step, the aim of this step is to install the DG unit as a FACTs device for voltage control and the DG is placed in all buses \& the voltage profile of the entire system in each installation is considered in the second step. After DG installation in each bus, the voltage profiles of all states are ranked from the best state to worst. Finally, two lists are considered to choose the best place to install the DG in a 33 bus test system to provide a good voltage profile.

\subsubsection{Computational Procedure}

- It is necessary to run the base case load flow.

- The voltage profile of the distribution system is specified after load flow, so the graph of voltage/bus no is drawn.

- From the graph (voltage/bus no), the priority list is formed: the sensitive buses (that should have a voltage control) in highest rank.

- Then DG is placed in each bus.

- It is necessary to run the load flow of the system after DG installation in each bus.

- Then the graphs of voltage profile of the 33 bus test system after placement of DG in each bus is drawn.

- Then another priority list is formed in this format: after comparing the graphs, it is necessary to rank them from the best profile to the worst one.

- The proper place of DG is chosen by comparing the priority list of Simulation Results: The load flow is done on the 33 bus distribution system and the voltages are shown in table 2.

Table 2. The voltages of the buses after load flow (before DG installation)

\begin{tabular}{|c|c|c|c|c|c|}
\hline $\begin{array}{c}\text { Bus } \\
\text { No }\end{array}$ & $\begin{array}{c}\text { Voltage } \\
(\text { PU) }\end{array}$ & $\begin{array}{c}\text { Bus } \\
\text { No }\end{array}$ & $\begin{array}{c}\text { Voltage } \\
(\text { PU) }\end{array}$ & $\begin{array}{c}\text { Bus } \\
\text { No }\end{array}$ & $\begin{array}{c}\text { Voltage } \\
(\text { PU) }\end{array}$ \\
\hline 1 & 1 & 12 & .95779 & 23 & .97490 \\
\hline 2 & .99633 & 13 & .95356 & 24 & .96351 \\
\hline 3 & .98238 & 14 & .95259 & 25 & .95627 \\
\hline 4 & .97809 & 15 & .95202 & 26 & .96283 \\
\hline 5 & .97387 & 16 & .94969 & 27 & .96139 \\
\hline 6 & .96398 & 17 & .94521 & 28 & .95546 \\
\hline 7 & .96327 & 18 & .94397 & 29 & .95213 \\
\hline 8 & .96259 & 19 & .99418 & 30 & .94925 \\
\hline 9 & .95840 & 20 & .97650 & 31 & .94469 \\
\hline 10 & .95771 & 21 & .97156 & 32 & .94398 \\
\hline 11 & .95766 & 22 & .96696 & 33 & .94350 \\
& & & & & \\
\hline
\end{tabular}




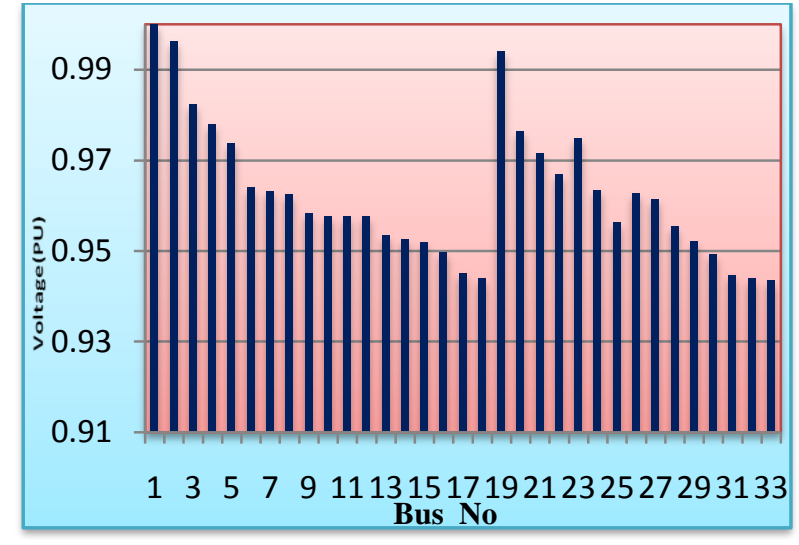

Figure 3: The voltage profile of 33 bus distribution system before DG installation. Voltage Range: .94350PU-1.0PU

Now according to the algorithm, the buses should be ranked from the minimum value of the voltage to the maximum one.

Table 3. The buses are ranked from the minimum value of voltage to maximum one (before DG installation)

\begin{tabular}{|c|c|c|}
\hline Bus No & Voltage(PU) & Rank \\
\hline $33,18,32,31,17$ & $.94350-.94521$ & 1 \\
\hline $30,16,15,29,14,13$ & $.94925-.95356$ & 2 \\
\hline $28,25,11,10,12,9$ & $.95546-.95840$ & 3 \\
\hline $27,8,26,7,24,6$ & $.96139-.96398$ & 4 \\
\hline 22,21 & $.96696-.97156$ & 5 \\
\hline $5,23,20,4$ & $.97387-.97809$ & 6 \\
\hline 3 & .98238 & 7 \\
\hline 19,2 & $.99418-.99633$ & 8 \\
\hline
\end{tabular}

The voltage profile of each state is found after DG installation on each bus. The voltage profiles are ranked from the best profile to worst one. Table 4 shows the ranking of voltage profile of buses after DG installation.

Table 4. Ranking of buses from best voltage profile to worst one after DG installation in each bus

\begin{tabular}{|c|c|}
\hline Bus No & Rank \\
\hline 32,33 & 1 \\
\hline 31,18 & 2 \\
\hline 17 & 3 \\
\hline 16,30 & 4 \\
\hline $15,29,14$ & 5 \\
\hline $28,25,12,13,11,10,9$ & 6 \\
\hline $8,27,7,26,6,24,22$ & 7 \\
\hline 21 & 8 \\
\hline $20,5,23,4$ & 9 \\
\hline 3 & 10 \\
\hline 19,2 & 11 \\
\hline
\end{tabular}

Comparing table $3 \& 4$, it is necessary to rank the best buses for DG installation.

Table 5. Optimum bus numbers for DG allocation

\begin{tabular}{|c|c|c|c|}
\hline Bus No & Rank & Bus No & Rank \\
\hline 32,33 & 1 & 12 & 8 \\
\hline 31,18 & 2 & $8,27,7,26,6,24$ & 9 \\
\hline 17 & 3 & 22 & 10 \\
\hline 16,30 & 4 & 21 & 11 \\
\hline $15,29,14$ & 5 & $20,5,23,4$ & 12 \\
\hline $28,25,11,10,9$ & 6 & 3 & 13 \\
\hline 13 & 7 & 19,2 & 14 \\
\hline
\end{tabular}

Table 5 shows the best locations for 2 MW DG installation to improve the voltage profile and voltage stability. The important point that can be already considered from the table 5 is that the optimum DG locations are the bus no $32 \& 33$. The other ranking in the table are not very important because it is not necessary to locate the best place. The voltage profiles of the 33 bus distribution system in the presence of DG in buses $32 \&$ 33 are shown below. It shows the voltage profile improvement.

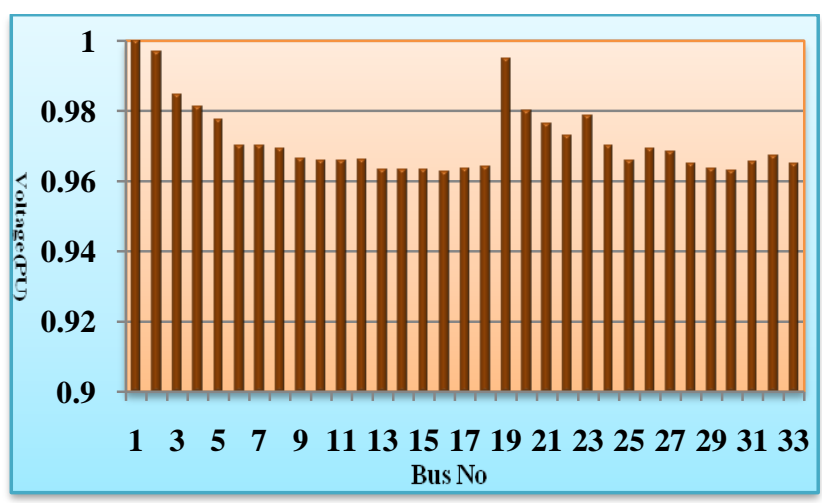

Figure 4: The voltages of buses after installation of DG unit at bus no 32. Voltage range: $96260 \mathrm{PU}-1.0 \mathrm{PU}$

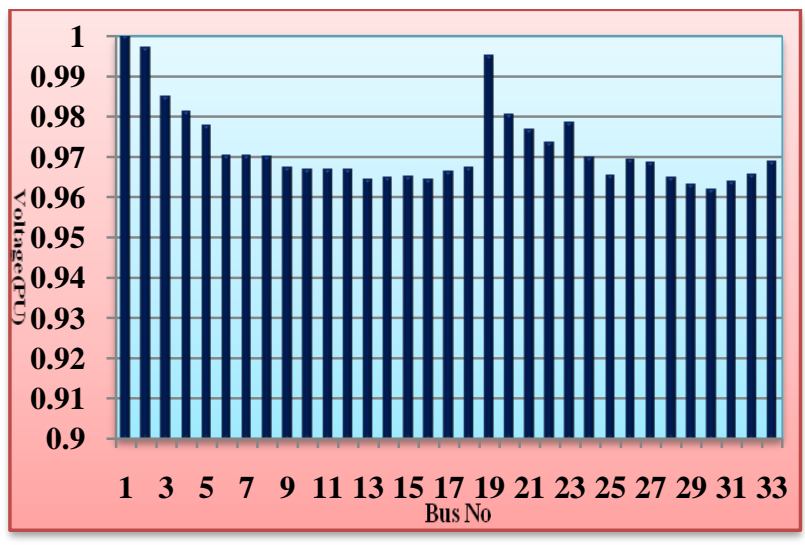

Figure 5: The voltages of buses after installation of DG unit at bus no 32. Voltage range: .96180PU-1.0PU 


\subsection{Second Procedure:}

Dispersed generation allocation for both loss reduction \& voltage profile improvement.

\subsubsection{Proposed Algorithm:}

To find the proper location of a DG unit in order to decrease the power loss \& voltage profile of the 33 bus distribution system is the aim of this procedure. It is necessary to determine a optimum place to install a DG unit for both loss reduction \& voltage improvement of the entire system. The algorithm is a combination of 2 sections. Sensitive buses to voltage (buses with low voltage magnitudes) are considered \& ranked in the first step. To install the DG as a FACTS device to have a voltage control is the aim of this step. It is essential to rank the minimum loss to maximum one after DG installation in each bus. Then it becomes easy to determine the optimum location for both loss minimization \& voltage improvement.

\subsubsection{Computational Procedure:}

- It is necessary to run the base case load flow.

- After DG installation in each bus, the approximate loss for each of them is studied \& it is essential to rank the buses from the minimum loss to the maximum one (a priority list).Then voltage magnitude of each bus is studied after load flow (before DG installation).

- It is essential to form a priority list of the buses from the sensitive buses (that have a low voltage magnitude) to the maximum one. It is necessary to form another priority list with comparing the lists in $3^{\text {rd }}, 4^{\text {th }}$ steps. It is now easier to choose the best place for installing the DG unit among the loss priority and voltage priority list.

- Then the DG in the best place is located and at last it is necessary to run the load flow program.

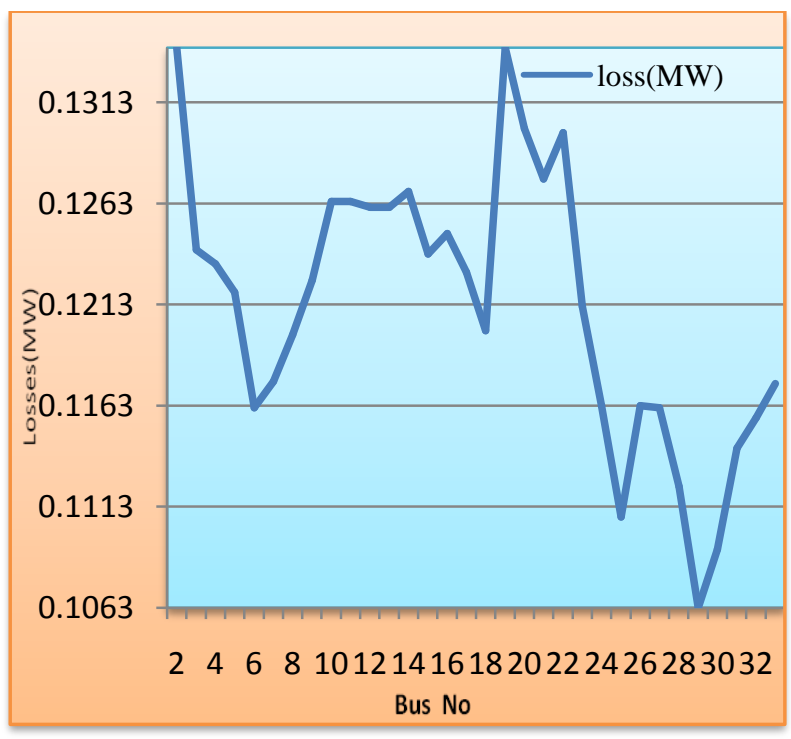

Figure 6: Losses of the 33 bus distribution system after installation of DG unit in each bus
Table 6. The priority list of buses for placement of DG unit from the loss view

\begin{tabular}{|c|c|c|}
\hline Bus No & Loss(MW) & Rank \\
\hline 29 & 0.1063 & 1 \\
\hline 30 & 0.1092 & 2 \\
\hline 25 & 0.1108 & 3 \\
\hline 28 & 0.1123 & 4 \\
\hline 31 & 0.1142 & 5 \\
\hline 32 & 0.1157 & 6 \\
\hline 6 & 0.1162 & 7 \\
\hline 27 & 0.1162 & 8 \\
\hline 24 & 0.1163 & 9 \\
\hline 26 & 0.1163 & 10 \\
\hline 33 & 0.1174 & 11 \\
\hline 7 & 0.1175 & 12 \\
\hline 8 & 0.1198 & 13 \\
\hline 18 & 0.1200 & 14 \\
\hline 23 & 0.1212 & 15 \\
\hline 5 & 0.1219 & 16 \\
\hline 9 & 0.1225 & 17 \\
\hline 17 & 0.1229 & 18 \\
\hline 4 & 0.1233 & 19 \\
\hline 15 & 0.1238 & 20 \\
\hline 3 & 0.1240 & 21 \\
\hline 16 & 0.1248 & 22 \\
\hline 12 & 0.1261 & 23 \\
\hline 13 & 0.1261 & 24 \\
\hline 10 & 0.1264 & 25 \\
\hline 11 & 0.1264 & 26 \\
\hline 14 & 0.1269 & 27 \\
\hline 21 & 0.1275 & 28 \\
\hline 22 & 0.1298 & 29 \\
\hline 20 & 0.1300 & 30 \\
\hline 2 & 0.1340 & 31 \\
\hline 19 & 0.1340 & 32 \\
\hline
\end{tabular}


Fig 6 shows the approximate total power loss for the 33 bus distribution system. In the 33 bus distribution test system, the best location is bus 29 with a total power loss of .1063 MW \& the second is bus 30 with slightly higher total power loss as shown in fig. 6. The priority list of the buses in order to placement of the DG unit to decrease the losses is shown in table 6.The voltage profile of the distribution system after load flow before DG placement is shown in table 7.

Table 7. The voltages of the buses after load flow (before DG installation)

\begin{tabular}{|c|c|c|c|c|c|}
\hline $\begin{array}{c}\text { Bus } \\
\text { No }\end{array}$ & $\begin{array}{c}\text { Voltage } \\
\text { (PU) }\end{array}$ & $\begin{array}{c}\text { Bus } \\
\text { No }\end{array}$ & $\begin{array}{c}\text { Voltage } \\
\text { (PU) }\end{array}$ & $\begin{array}{c}\text { Bus } \\
\text { No }\end{array}$ & $\begin{array}{c}\text { Voltage } \\
(\text { PU) }\end{array}$ \\
\hline 1 & 1 & 12 & .95779 & 23 & .97490 \\
\hline 2 & .99633 & 13 & .95356 & 24 & .96351 \\
\hline 3 & .98238 & 14 & .95259 & 25 & .95627 \\
\hline 4 & .97809 & 15 & .95202 & 26 & .96283 \\
\hline 5 & .97387 & 16 & .94969 & 27 & .96139 \\
\hline 6 & .96398 & 17 & .94521 & 28 & .95546 \\
\hline 7 & .96327 & 18 & .94397 & 29 & .95213 \\
\hline 8 & .96259 & 19 & .99418 & 30 & .94925 \\
\hline 9 & .95840 & 20 & .97650 & 31 & .94469 \\
\hline 10 & .95771 & 21 & .97156 & 32 & .94398 \\
\hline 11 & .95766 & 22 & .96696 & 33 & .94350 \\
\hline
\end{tabular}

Table 8. The buses are ranked from the minimum value of voltage to maximum one (before DG installation)

\begin{tabular}{|c|c|c|}
\hline Bus No & Voltage(PU) & Rank \\
\hline $33,18,32,31,17$ & $.94350-.94521$ & 1 \\
\hline $30,16,15,29,14,13$ & $.94925-.95356$ & 2 \\
\hline $27,8,26,7,24,6$ & $.96139-.96398$ & 4 \\
\hline 22,21 & $.96696-.97156$ & 5 \\
\hline $5,23,20,4$ & $.97387-.97809$ & 6 \\
\hline 3 & .98238 & 7 \\
\hline 19,2 & $.99418-.99633$ & 8 \\
\hline
\end{tabular}

Comparing two priority lists table $6 \&$ table 8 , the new priority (table 9) is made that shows the proper places to install the DG unit for decreasing the losses \& improving the voltage profile.

Table 9. The resulted priority list for placement of DG unit

\begin{tabular}{|c|c|c|c|}
\hline Bus No & Rank & Bus No & Rank \\
\hline 29,30 & 1 & 13 & 12 \\
\hline 31,32 & 2 & 12 & 13 \\
\hline 25,28 & 3 & 14 & 14 \\
\hline $6,27,24,26$ & 4 & 10,11 & 15 \\
\hline 33 & 5 & 21,22 & 16 \\
\hline 18 & 6 & 23,5 & 17 \\
\hline 7,8 & 7 & 4 & 18 \\
\hline 17 & 8 & 20 & 19 \\
\hline 9 & 9 & 3 & 20 \\
\hline 15 & 10 & 2,19 & 21 \\
\hline 16 & 11 & \multicolumn{2}{|l}{} \\
\hline
\end{tabular}

It is concluded that optimum places for installing DG unit are in buses 29, 30 because the places are in the first rank in loss priority list and second rank in voltage priority list. The new priority list (Table 9) that is resulted from the last table (last priority list), helps to determine the optimum place to install the DG unit to maintain a minimum loss as well as improve the voltage profile. Voltage profile of the 33 bus distribution system after DG installation in bus no 29, 30 is shown in fig 7, 8.After examine it is concluded that the voltage profile is better than last state (before DG installation).

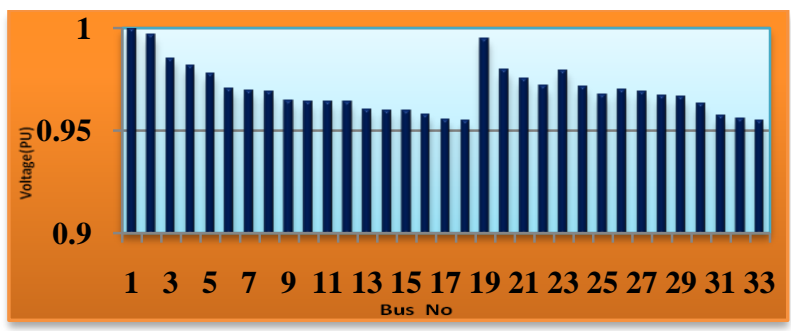

Figure 7: The voltages of buses after installation of DG unit at bus no 32. Voltage range: $0.95460 \mathrm{PU}$ - 1PU

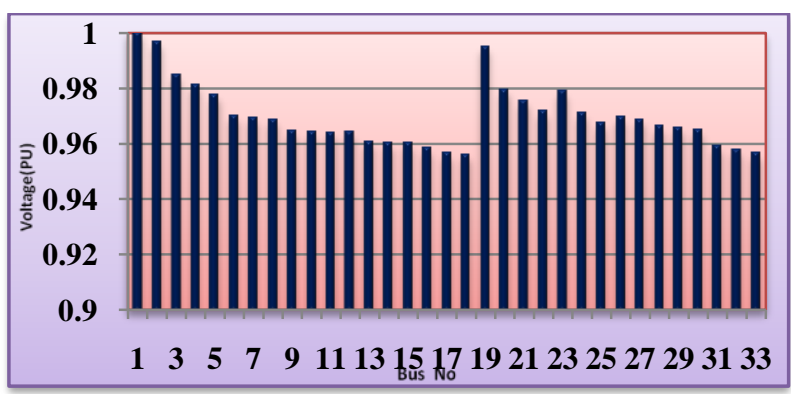

Figure 8: The voltages of buses after installation of DG unit at bus no 30.Voltage range: $0.95612 \mathrm{PU}$ - 1PU

\subsection{Third Procedure: Optimum DG Size}

If it is concerned about power quality of the primary \& secondary distribution system, it will only consider the DG sizes less than 10MW. Distributed generator larger than this is typically interconnected at transmission voltage where the system is designed to accommodate many generators.

\subsubsection{Proposed Algorithm}

To find the optimum size of a DG unit in order to decrease the power loss as well as to maintain a good voltage profile of the 33 bus distribution system is the aim of this procedure. To determine the optimum size it is necessary to install different sizes of DGs at optimum place (the place where total system loss is minimum).

\subsubsection{Computational Procedure}

After determining optimum DG location for minimizing total system loss and also for voltage profile improvement, the following steps are followed for finding optimum DG size.

- In this procedure different size of DG is placed at the optimum location(i.e. at bus no 29 of the 33 bus distribution system)

- It is also necessary to study the voltage profile\& total loss of the system after installing DG of different size. The DG which provides a good voltage range with a minimum total power loss, acceptable as an optimum size. 
Table 10. Comparison of 2MW DG with different sizes

\begin{tabular}{|c|c|c|}
\hline DG SIZE & $\begin{array}{c}\text { VOLTAGE } \\
\text { RANGE(PU) }\end{array}$ & $\begin{array}{c}\text { TOTAL } \\
\text { LOSS(MW) }\end{array}$ \\
\hline $1 \mathrm{MW}$ & $.94920-1$ & .115 \\
\hline $2 \mathrm{MW}$ & $.95460-1$ & .106 \\
\hline $3 \mathrm{MW}$ & $.95968-1$ & .109 \\
\hline $4 \mathrm{MW}$ & $.96457-1$ & .123 \\
\hline $5 \mathrm{MW}$ & $.96843-1$ & .148 \\
\hline $6 \mathrm{MW}$ & $.97183-1$ & .185 \\
\hline $7 \mathrm{MW}$ & $.97464-1$ & .231 \\
\hline $8 \mathrm{MW}$ & $.97563-1$ & .251 \\
\hline $9 \mathrm{MW}$ & $.97563-1$ & .251 \\
\hline
\end{tabular}

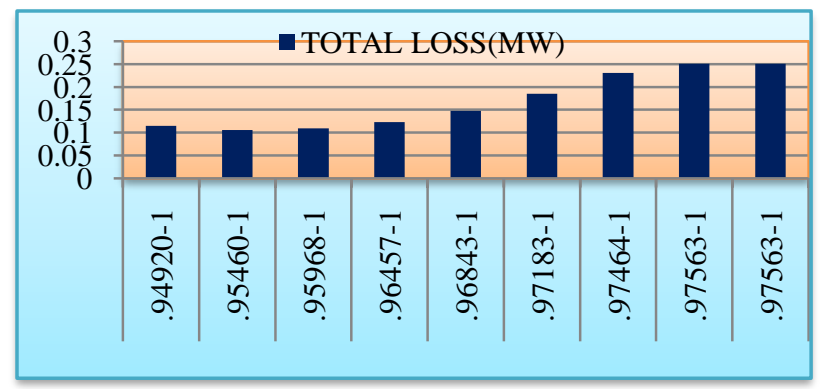

Figure 9: Losses with respect of different sizes of DGs

The marginal under voltage range is $.95-.98 \mathrm{PU}$, bus voltage below this range is known as critical under voltage. The 33 bus distribution system has a total loss of .137MW \& a voltage range of .9435-1pu without DG. Bus voltage of .9435pu is below the lower limit of marginal under voltage, called critical under voltage. So the voltage profile $(.9435-1 \mathrm{pu})$ of 33 bus distribution system without DG provides a worse voltage profile \& the total loss of the system is high. It is necessary to install a optimum size of DG at optimum location to improve the voltage profile as well as to minimize loss of the 33 bus test system. The optimum size of DG must be $2 \mathrm{MW}$ for the 33 bus distribution system, it is concluded after studying the table 10 due to the following reasons:-

\subsubsection{1MW DG Size}

It is shown in table 10, installation of $1 \mathrm{MW}$ DG at bus no 29 (optimum location) results in total loss of $0.115 \mathrm{MW}$, which is greater than the minimum loss of $0.106 \mathrm{MW}$ (installation of 2MW DG at optimum location). The voltage range is .94920$1 \mathrm{PU}$ and minimum value of bus voltage is $.94920 \mathrm{PU}$ which is less than .95PU (lower limit) of marginal under voltage, called critical under voltage. As a result the voltage profile becomes a worse voltage profile. For these reasons, installation of 1MW DG is not acceptable at optimum location to improve voltage profile $\&$ to minimize loss of the 33 bus distribution system.

\subsubsection{2MW DG Size}

It is shown in table 10, after installation of $2 \mathrm{MW}$ DG in a 33 bus distribution system the loss is.106MW \& the voltage range is $.95460-1 \mathrm{PU}$ which does not violate the marginal under voltage range. For this reason installation of $2 \mathrm{MW}$ DG in the 33 bus test system provides a good voltage profile as well as the total loss of the system becomes minimum. So $2 \mathrm{MW}$ DG is acceptable as an optimum size to improve the voltage profile as well as loss reduction for the 33 bus test system.

\subsubsection{3MW DG Size}

It is shown in table 10, after installation of 3MW DG at optimum location, the voltage range is .95968-1PU which provides a good voltage profile \& the loss is .109MW which is greater than the minimum loss of .106MW (installation of 2MW DG at optimum location).

So installation of $3 \mathrm{MW}$ DG is not acceptable as an optimum size.

\subsubsection{4MW DG Size}

It is shown in table 10, the voltage range is .96457-1PU \& the loss is .123MW (at optimum location) after installation of 4MW DG at optimum location, in a 33 bus distribution system. Here total loss .123MW is greater than the minimum loss of $.106 \mathrm{MW}$. It is necessary to improve the voltage profile as well as to maintain a minimum loss of a test system.

So installation of 4MW DG is not acceptable as an optimum size.

\subsubsection{5MW DG Size}

It is shown in table 10, after installation of 5MW DG in a 33 bus distribution system, the voltage range is .96843-1 PU, which provides a good voltage profile \& the loss is .148MW (at optimum location) which is greater than the minimum loss of.106MW

So installation of 5MW DG is not acceptable as an optimum size.

\subsubsection{6MW DG Size}

In this case the voltage range is $.97183-1 \mathrm{PU}$ which provides a good voltage profile \& the loss is.185MW (at optimum location) after installation of 6MW DG in a 33 bus distribution system. Here the total loss $0.185 \mathrm{MW}$ is greater than the minimum loss of.106MW (installation of $2 \mathrm{MW}$ DG at optimum location) \& also higher than the total loss of .137MW (before DG installation).

So installation of 6MW DG is not acceptable as an optimum size.

\subsubsection{7MW DG Size}

It is shown in table 10 , the voltage range is $.97464-1 P U \&$ the loss is .231MW (at optimum location) after installation of $7 \mathrm{MW}$ DG in a 33 bus distribution system. Installation of 7MW DG provides a good voltage profile, but the total loss is $.231 \mathrm{MW}$, which is greater than the minimum loss of.106MW (installation of 2MW DG at optimum location) \& also higher than the total loss of .137MW (before DG installation).

So installation of 7MW DG is not acceptable as an optimum size.

\subsubsection{8MW DG Size}

It is shown in table 10 , the voltage range is $.97563-1 \mathrm{PU} \&$ the loss is .251MW (optimum location) after installation of $8 \mathrm{MW}$ DG in a 33 bus distribution system, which is greater than the minimum loss of.106MW (installation of 2MW DG at optimum location) \& also higher than the total loss of .137MW (before DG installation). So installation of 8MW DG is not acceptable as an optimum size. 


\subsubsection{9MW DG Size}

It is shown in table 10, after installation of 9MW DG at optimum location in a 33 bus distribution system, the voltage range is $.97563-1 \mathrm{PU}$ which provides a good voltage profile \& the loss is $.251 \mathrm{MW}$ which is greater than the minimum loss of.106MW.

So installation of 9MW DG is not acceptable as an optimum size.

\section{CONCLUSION}

The size \& location of DGs are crucial factors in the application of DG for loss minimization \& voltage improvement respectively. This thesis presents a load flow based simulation using ETAP to find out the optimum location \& optimum size of DG unit for voltage profile improvement \& minimizing power losses in the 33 bus distribution network. The installation of DG unit at non optimal places can result in an increase in system losses; implying in an increase in costs \& resulting low or over voltages in the network, having an effect opposite to the desired. For that reason, the use of a methodology capable of analyzing the influence on some system characteristics of DG allocation can be very useful for the system planning engineer when dealing with the increase of DG penetration that is happening nowadays. The proposed algorithm is already discussed in this thesis, more accurate than previous methods \& can identify the best location for single DG placement in order to improve the voltage profile \& to minimize total power losses. The proposed method has also used to determine the optimum size \& location of DG unit, taking into consideration the power cost $\&$ available power ratings of DGs. Results prove that the optimum size \& location of a DG can save a huge amount of power. Power system deregulation and shortage of transmission capacities have led to an increase interest in Distributed generations (DGs) sources. The optimal location of DGs in power systems is very important for obtaining their maximum potential benefits. In this project work, only optimum location of DG has been determined for loss reduction and voltage improvement in the 33 bus distribution system. For proper allocation of DG, size of DG also plays an important rule. Size of DG effects losses and voltage profile of the distribution system. Also a comparative study can be done between different techniques like Analytical method, Optimum power flow method, Evolutionary techniques like Genetic Algorithm(GA), Fuzzy logic etc. for finding optimum size and location of DG for loss minimization and voltage improvement for the 33 bus distribution system.

\section{APPENDIX}

DG unit: $2 \mathrm{MW} \& 1.24$ Mvar.

\section{REFERENCES}

[1] F.Gonzalez-Longatt,C.Fortoul " Review Of The Distributed Generation Concept." Attempt Of Unification.

[2] Anshu Bharadwaj and Rahul Tongia, Member, IEEE "Distributed Power Generation: Rural India-A Case Study".

[3] A.Kazemi, \& M.Sadeghi,“ Distributed Generation Allocation For Loss Reduction \& Voltage Improvement."

[4] W.EI-Khattam, K.Bhattacharya, Y.HEGAZY,M.M.A Salama, " Optimal investment planning for distribution generation in a competitive electricity market, "IEEE Transactions on power systems, vol.19, no.3,Aug 2004.
[5] S.W.ILLERHAUS ,J.S. Versteg, "Optimal operation of industrial CHP based power systems in liberalized energy markets, " IEEE Industry Applications conference, 2000, vol.2, pp.901-908

[6] R.E Brown et al " Sitting distribution generation to defer T\&D expansion "IEEE/PES Transmission and Distribution conference and exposition, 2001.vol2,pp.622627.

[7] B.Kuri, F.Li, "Distributed generation planning in the deregulated electricity supply industry “ IEEE/PES General meeting , 2004, vol.2, pp.2085-2089.

[8] N.S.Rau, F.Zeng, “Adequacy and responsibility of locational generation and transmission-optimization procedures "IEEE Tran On Power Systems, vol. 19, No.4, pp.2093-2101, Nov 2004.

[9] EIA, Department Of Energy, “ Annual energy outlook 2005”, Feb 2005.

[10] M.E.H Golshan, S.A. Arefifar, "Distributed generation, reactive sources and network configuration planning for power and energy loss reduction", IEE proceedings on generation, transmission and distribution, 16 March 2006 , vol.153, issue 2 ,pp.127-136.

[11] A.Cano, F.Jurado, “ Optimum location of biomass-fuelled gas turbines in an electric systems",2006 IEEE power Engineering Society General Meeting, 18-22 June 2006.

[12] M.Gandomkar, M.Vakilian, M.Ehsan, "A combination of genetic algorithm and simulated annealing for optimal DG allocation in distribution networks", 2005 Canadian conference on electrical and computer engineering,1-4 May 2005, pp.645-648.

[13] M.R.Vallem,J.Mitra,"Sitting and sizing of distributed generation for optimal micro grid architecture",2005 proceedings of the $37^{\text {th }}$ annual North America power symposium, 23-25 Oct. 2005, pp.611-616.

[14] M.Pipattanasomporn, M.Willingham, S.Rahman, "Implications of on-site distributed generation for commercial/industrial facilities",IEEE Tran. On power systems, Feb 2005, vol 20, Issue 1, pp.206-212.

[15] B.Kuri, M.Redfern , F.LI, “ Optimization of rating and positioning of dispersed generation with minimum network disruption”,2004 IEEE power engineering society general meeting, 6-10 June 2004, vol. 2,pp. 2074-2078.

[16] G.Celli, E.Chiani, S.Mocci, F.Pillo, "A multi objective formulation for the optimal sizing and sitting embedded generation in distribution networks", 2006 IEEE Bologna power tech conference proceedings, Bologna,23-26 June 2003, vol.1

[17] Gopia Naik S. ${ }^{1+}$, D. K Khatod ${ }^{2}$ and M.P. Sharma ${ }^{2}$, "Optimal Allocation Of Distributed Generation in Distribution System For Loss Reduction."

[18] L.Ramesh, S.P Chowdhury, S. Chowdhury, A.A Nataranjan, C.T. Gaunt " Minimization Of power Loss in Distribution Networks By Different Techniques."

[19] A.Kazemi, and M. Sadeghi, " A load flow based method for optimal location of Dispersed Generation Units". 